\title{
La política exterior de la Unión Europea en Asia central: de la condicionalidad política al pragmatismo*
}

\author{
The Foreign Policy of the European Union \\ in Central Asia: From Political Conditionality \\ to Pragmatism
}

\section{Manuel de Jesús Rocha Pino**}

SUMARIO: I. Introducción. II. La trayectoria de la presencia europea en Asia central. III. Los comunicados estratégicos sobre Asia central. IV. Las potencias externas y el proceso de apropiación conceptual de Asia central durante la Posguerra Fría: una comparación con el caso europeo. V. Consideración final.

* Artículo recibido el 15 de julio de 2011 y aprobado para publicación el 28 de septiembre de 2011.

** Universidad Autónoma de Barcelona. El presente artículo ha sido completado durante estancias de investigación realizadas en el Centro de Investigaciones Interdisciplinarias en Ciencias y Humanidades (CEIICH) de la UNAM y en el Nordic Institute of Asian Studies (NIAS) de la Universidad de Copenhague. El autor agradece al embajador Jorge Eduardo Navarrete del CEIICH y al doctor Geir Helgesen del NIAS el apoyo otorgado durante dichas estancias. La investigación fue realizada gracias a una beca de estudios en el extranjero proporcionada por el Consejo Nacional de Ciencia y Tecnología de México (Conacyt). Todos los errores y omisiones corresponden al autor. 
RESUMEN: El objetivo de la investigación es realizar una descripción de la política exterior instrumentada por la Unión Europea en su aproximación hacia los países ex soviéticos de Asia central a partir de 1991 y su evolución mantenida hasta el presente. Durante este periodo las políticas de aproximación europea hacia la región centroasiática han cambiado de un modelo de donación de ayuda financiera y técnica condicionada a la articulación de un enfoque más bien pragmático que considera prioritaria la promoción de los intereses económicos y de seguridad europeos.

En el trabajo se describen las ideas que se han producido en Europa sobre Asia central, buscándose responder a una pregunta de investigación básica: ¿qué ideas europeas sobre Asia central han servido como guías en la política exterior de la UE hacia esa región?

Palabras clave: asimetría, Programa TACIS, acuerdos de asociación y cooperación, condicionalidad política, poder normativo

ABSTRACT:This research's objective is to describe the trajectory of the European Union political approach towards the ex soviet Central Asian countries since 1991 and its evolution maintained until the present. The EU policies towards Central Asia have changed from a model of European financial and technical aid granted under conditional criteria to a relationship based on a pragmatic approach. The research summarizes the ideas generated from Europe about Central Asia, seeking to answer a basic question: Which European ideas on Central Asia have served as guides in the UE's foreign policy towards the region?

Descriptors: asymmetry, TACIS Programme, partnership and cooperation agreements, political conditionality, normative power.

RÉSUMÉ: L'objectif de la recherche est faire une description de la politique étrangère mise en ouvre par l'Union Européenne dans son approche vers les pays ex-soviétiques de l'Asie centrale depuis 1991 et son évolution maintenue jusqu'à aujourd'hui. Pendant cette période, les politiques d'approche européenne vers la région d'Asie centrale ont changé d'un modèle de donation d'assistance financière et technique à l'articulation d'une approche pragmatique qui considère prioritaire à la promotion des intérêts économiques et la sécurité européens.

LE document décrit les idées qui ont eu lieu en Europe sur l'Asie centrale, en cherchant la réponse à une question de recherche fondamentale: quelles idées européennes sur l'Asie centrale ont servi de guides dans la politique étrangère de l'UE vers cette région?

Mots-clés: l'asymétrie, Programme TACIS, les accords de partenariat et de coopération, de la conditionnalité politique, le pouvoir normatif. 


\section{INTRODUCCIÓN}

A continuación se realizará una descripción de la aproximación política realizada por la Unión Europea (UE) hacia los países ex soviéticos de Asia central y la evolución que ha mantenido hasta el momento. La aproximación europea hacia la región centroasiática ha evolucionado desde un modelo de transferencia de normas europeas mediante la condicionalidad de cierta ayuda económica y técnica hacia la región a la articulación de una relación que aspira a basarse en criterios orientados de manera más bien pragmática (debido a la falta de efectividad del primer modelo) con el fin de cooperar en ciertas prioridades e intereses estratégicos para la UE como la seguridad energética o la lucha contra el terrorismo y el extremismo; sin embargo, como se tratará de demostrar en el trabajo, hasta el momento los criterios de la ayuda condicionada siguen siendo una parte esencial en las relaciones de la UE con la región.

En la actualidad la relación entre la UE y los países centroasiáticos se sitúa en una tensión entre la promoción de los valores normativos europeos y la salvaguarda de ciertos intereses económicos y de seguridad (no necesariamente complementarios), en una condición que se ha gestado desde hace dos décadas: desde una perspectiva crítica, esta situación ha sido producto de una aproximación políticamente asimétrica justificada en un conjunto de ideas preconcebidas que se han elaborado desde Europa sobre Asia central. Lo anterior se debe a que los conceptos europeos sobre Asia central en ocasiones han confeccionado una imagen que pudiera presentarse de manera instrumental para los intereses y necesidades de Europa, lo que ha producido una distorsión cognitiva en lo referente a las características objetivas de los países de aquella región entre los medios oficiales de la UE.

En el trabajo se busca realizar un análisis de las ideas generadas desde los medios oficiales de la UE sobre Asia central durante la Posguerra Fría, cómo dichas ideas han determinado las políticas europeas de cooperación y la trascendencia de dicho proceso para el entorno regional. 


\section{LA TRAYECTORIA DE LA PRESENCIA EUROPEA EN ASIA CENTRAL}

1. La cooperación para el desarrollo en la relación euro-centroasiática: la condicionalidad como expresión de una relación asimétrica

Tras la disolución de la Unión Soviética en 1991, los cinco países ex comunistas ubicados en lo que es considerado como parte de Asia central contemporánea (Kazajstán, Kirguistán, Tayikistán, Turkmenistán y Uzbekistán) iniciaron un proceso de construcción nacional a partir de su particular condición poscolonial. Las prioridades en dicho proceso se orientaron al desarrollo y consolidación de sus instituciones internas así como a la obtención del reconocimiento internacional como entidades soberanas e independientes. Durante los primeros años de su independencia, las nuevas repúblicas advirtieron que el fortalecimiento de sus instituciones se relacionaba directamente con una necesaria diversificación de sus relaciones con el mundo exterior, particularmente más allá de la esfera de influencia de la Federación Rusa (entonces concentrada en sus propias necesidades y proyectos de reforma) y con la ampliación de sus relaciones de cooperación internacional. ${ }^{1}$ Para fortalecer su soberanía, los países centroasiáticos trataron de atraer la atención de capitales estadounidenses, europeos y japoneses con el fin de iniciar procesos de reforma económica similares a los que se impulsaban en Europa del Este; sin embargo, durante esos primeros años, la región centroasiática no fue una prioridad en los planes de inversión del capital internacional:

... la prioridad era ampliar lazos sólidos con la economía global y atraer la inversión extranjera. Por lo tanto, la década de los noventa fueron los años en que

1 Aunque los países centroasiáticos pertenecen a una variedad de organizaciones internacionales, hasta el momento no ha existido una organización de cooperación internacional o un proyecto de integración que agrupe únicamente a las cinco repúblicas ex soviéticas. Algunas de estas organizaciones presentes en la región son: la Comunidad Económica Euroasiática, la Organización de Cooperación de Asia Central, la Organización del Tratado de Seguridad Colectiva, la Organización de Cooperación de Shanghai y la Comunidad de Estados Independientes. 
Asia central se mostró más abierta a la influencia de Occidente. Sin embargo, esta oportunidad fue ampliamente ignorada. ${ }^{2}$

La presencia europea en la región centroasiática fue especialmente modesta durante este primer periodo, pues Alemania fue el único país miembro de la Comunidad Europea en inaugurar representaciones diplomáticas en todos los países de la región: Francia y Reino Unido contaban con algunas embajadas y la mayoría de los países europeos prefirieron tener a un representante, regularmente ubicado en Moscú o Ankara, para encargarse de los asuntos concernientes a las cinco repúblicas de Asia central. La consecuencia de la actitud anterior fue el poco desarrollo de los vínculos bilaterales y la no inclusión de los países centroasiáticos en el Consejo de Europa (si bien fueron admitidos en la Organización para la Seguridad y la Cooperación en Europa - OSCE - y en el programa de Asociaciones para la Paz de la OTAN). Por otra parte, la presencia institucional de la Unión Europea fue igualmente limitada; la primera delegación de la UE en la región fue abierta en Kazajstán en 1994, teniendo bajo su responsabilidad a los asuntos relacionados con Kirguistán y Tayikistán, países en los que posteriormente fueron abiertas dos suboficinas, al mismo tiempo que la región era incluida en el programa de ayuda para el exterior Tacis, destinado a los países ex soviéticos (Technical Assistance to the Commonwealth of Independent States, por sus siglas en inglés o denominado TACIS hasta 1993). ${ }^{3}$

Además del programa TACIS, en el desarrollo de la aproximación inicial de la UE hacia la región pueden resaltarse otras dos herramientas que han servido como el marco legal e institucional para el desarrollo de las relaciones entre la organización y los países de Asia central: los Acuerdos de Cooperación y Asociación (Partnership and Cooperation Agreements o PCA por sus siglas en inglés) establecidos de manera bilateral por la UE con algunos de los países de la región así como un conjunto de programas de asistencia técnica instrumentados desde la década de los noventa como el TRACECA, el INOGATE, entre otros.

\footnotetext{
Melvin, Neil J., “The European Union's Strategic Role in Central Asia”, en Melvin, Neil J. (ed.), Engaging Central Asia:The European Union's New Strategy in the Heart of Eurasia, Bruselas, Centre for European Policy Studies, 2008, p. 2.

3 Idem.
} 
Ambas modalidades de cooperación, ya sea el programa de ayuda orientado regionalmente TACIS o los acuerdos bilaterales _ PCA contribuyeron a elaborar una concepción europea sobre Asia central que terminó orientando la formulación de las políticas de ayuda entre la burocracia europea radicada en Bruselas: dicha concepción, la cual se ha mantenido implícita en los proyectos de ayuda europea hacia la región hasta el momento, ha consistido en visualizar a Asia central como una región unitaria, con países sin apenas rasgos de diferenciación entre ellos, lo cuales podían ser receptivos de los programas europeos de ayuda para el tercer mundo. La confusión cognitiva generada en las apreciaciones oficiales de la UE sobre Asia central ha sido una de las principales razones que originaron la falta de coherencia institucional de los programas de ayuda europeos: algo expresado en una falta de correlación entre los objetivos generales de los programas y una información incompleta sobre la realidad empírica de cada país (necesaria a tomar en cuenta para la instrumentación de la ayuda), teniendo como consecuencia resultados finales limitados.

Es claro que la interpretación política que determinó los planes de ayuda europeos ignoró algo complejo: la realidad constituida por las diferentes sociedades en el interior de cada país centroasiático, producto de la compleja diversidad étnica y cultural existente entre sus habitantes, las trayectorias históricas de cada país (en ocasiones compartida regionalmente, debido en primera instancia por su pertenencia a la antigua URSS, pero con características muy particulares en cada caso) así como la diversa condición poscolonial que ha tenido que enfrentar cada Estado. Considerar el contexto anterior es esencial para el estudio de las relaciones entre la UE y la región centroasiática: la historia de estas relaciones es la trayectoria de un conjunto de programas de ayuda, en los que Asia central ha sido considerada una región del Tercer Mundo que ha podido ser conceptualizada en términos europeos de acuerdo a las necesidades e intereses del actor con mayor poder; una condición estructuralmente asimétrica que ha sido el fundamento de la relación euro-centroasiática.

A continuación se describirá la evolución de los programas de ayuda técnica concebidos regionalmente y las características de los PCA establecidos bilateralmente entre la UE y los países centroasiáticos. Pre- 
viamente, debido a las características de la historia de las relaciones de cooperación euro-centroasiáticas, se realizará una definición del concepto de condicionalidad y del funcionamiento de dicho mecanismo de coerción en el sistema europeo de cooperación para el desarrollo.

\section{El concepto de condicionalidad}

y los programas europeos de ayuda para Asia central

Existen diversas organizaciones e instituciones internacionales que hacen uso de la condicionalidad. Si bien las cláusulas de condicionalidad se pueden asociar normalmente con instituciones económicas y financieras como el Fondo Monetario Internacional (FMI) o el Banco Mundial, a partir del fin de la Guerra Fría aumentó considerablemente el número de los organismos internacionales que comenzaron a incluir esta clase de requerimientos en sus negociaciones con otros actores.

Jeffry T. Checkel describe a la condicionalidad como:

El uso de incentivos para alterar el comportamiento o las políticas de un Estado; es una estrategia básica a través de la cuál las instituciones internacionales promueven el compromiso para el cumplimiento de las normas (compliance) entre los gobiernos nacionales... es un acuerdo mutuo en el cual un gobierno toma o promete tomar ciertas acciones políticas. ${ }^{4}$

Por su parte, para F. Schimmelfennig la condicionalidad puede definirse como "una estrategia basada sobre la influencia social o el reforzamiento en lugar de la persuasión". ${ }^{5}$ La condicionalidad busca modificar la conducta de los actores utilizando métodos basados en el reforzamiento del comportamiento que será considerado (y prescrito) como aceptable por parte del actor con mayor poder en una relación; el re-

4 Checkel, Jeffrey T., "Compliance and Conditionality”, ARENAWorking Papers Series 15/09, Oslo, Oslo University, 2000, s. p., en: http://www.arena.uio.no/publications/working-papers 2000/wp00_18.htm.

5 Schimmelfennig, Frank, "The EU: Promoting Liberal-Democracy through Membership Conditionality”, en Flockhart, Trine (ed.), Socializing Democratic Norms: the Role of International Organizations for the Construction of Europe, Basingstoke, Palgrave Macmillan, 2005, p. 106. 
forzamiento de la conducta en la relación condicionada significa "una forma de control social, el comportamiento que sigue las reglas aceptadas socialmente es recompensado y el comportamiento antisocial es sancionado". ${ }^{6}$ La condicionalidad puede ser definida como una estrategia de reforzamiento por recompensa.

Durante el presente periodo de Postguerra Fría se ha apreciado una multiplicación en el uso de la condicionalidad "como un propósito subyacente”, con el fin de impulsar la promoción de la reforma política e institucional a la par con las reformas de naturaleza económica. En particular, el periodo de Postguerra Fría coincidió con las primeras aproximaciones europeas hacia los países centroasiáticos independientes; en esta coincidencia puede establecerse el contexto del uso de la condicionalidad como una parte medular de la relación entre la UE y los países de Asia central: la ayuda condicionada sirvió como un elemento básico del modelo en los primeros acercamientos europeos hacia la región, consistente en un conjunto de programas de ayuda que era ofrecida a cambio de que los actores involucrados mostraran una conformidad en la aceptación y el cumplimiento de las normas prescritas por la UE.

De acuerdo a Checkel, la condicionalidad adquiere tres aspectos o "modalidades":

1) Las denominadas “precondiciones”:

consistentes en las acciones políticas que se acuerdan durante las negociaciones entre el organismo internacional y el gobierno nacional, las cuales deben ser realizadas antes de que se aprueben las condiciones de un crédito (en el caso del FMI) o las subvenciones por la membresía en una organización (en el caso de la incorporación de un país en el proceso de ampliación de la UE). ${ }^{7}$

2) Posteriormente se establecen las acciones iniciales a cumplir para continuar con el proceso de negociación:

referidas frecuentemente como los criterios de actuación o los requerimientos legales, en conformidad con estas acciones iniciales que deben cumplirse

6 Ibidem, pp. 106 y 107.

7 Checkel, Jeffrey T., op. cit. p. s/n. 
los gobiernos tienen acceso a un crédito; para las organizaciones como la UE tales acciones pueden ser un requerimiento legal para la adopción del aequis comunitario previamente a que las negociaciones para la membresía puedan continuar a la siguiente etapa. ${ }^{8}$

3) Otra modalidad de la condicionalidad son las disposiciones políticas: compromisos adicionales contenidos en el acuerdo general, pero que no son precondiciones en las acciones iniciales que se han demandado. ${ }^{9}$

De la misma manera, la condicionalidad es un concepto que puede ser diferenciado, categorizado y medido de acuerdo a tres aspectos: 1) "la condicionalidad puede tener una naturaleza ex post al utilizarse, de manera usual, como una forma del derecho internacional: las condiciones deben cumplirse después de la ratificación de la firma de un acuerdo, tratado o contrato. Por lo contrario, una condicionalidad con una naturaleza ex ante significa que el cumplimiento de las obligaciones debe realizarse con anterioridad o justo antes de que el acuerdo sea firmado"; 2) la condicionalidad puede ser bilateral o multilateral; 3) la condicionalidad puede ser positiva o negativa en esencia. La condicionalidad negativa significa que la influencia del donador ya ha existido de manera previa al acuerdo: el donador amenaza con cambios al acuerdo si no se cumplen sus condiciones. Por otra parte, la condicionalidad positiva posee una naturaleza ex ante. En este caso el donador promete cierto tipo de ayuda para llegar a un compromiso con el receptor, dependiendo de cada caso; la característica común de la condicionalidad positiva, en el caso de la UE, es su naturaleza asimétrica: "El actor receptor necesita recursos a cambio de reformas, y el actor donador necesita la reubicación de recursos económicos y prevenir conflictos en su vecindario”. ${ }^{10}$ De acuerdo a Veebel

por lo general la condicionalidad puede ser considerada un subcomponente teórico o un método explicativo de las relaciones entre dos actores. La condiciona-

8 Idem.

9 Idem.

10 Veebel, Viljar, “European Union's Positive Conditionality Model in Pre-accesion Process”, Trames Tallin, vol. 13, núm. 3, 2009, pp. 209 y 210. 
lidad posee un conjunto de herramientas para enlazar al Estado o la organización internacional, o los beneficios deseados por otro Estado, para el cumplimiento de ciertas condiciones. ${ }^{11}$

Por su parte, Checkel define al cumplimiento de las normas (compliance) como "la medida por la cual los agentes actúan de acuerdo y en cumplimiento de las condiciones prescritas por las instituciones internacionales", así como los motivos y actitudes que los orientan a actuar de acuerdo con las condiciones de las instituciones internacionales.

Idealmente tres factores determinan el cumplimiento normativo de los actores con menor poder hacia las condiciones prescritas en los acuerdos:

1) La forma en que los miembros de las instituciones politizan la condicionalidad: "paulatinamente los Estados saben que pueden obtener "algo a cambio de nada", una situación que puede socavar toda la lógica de incentivos que se encuentra detrás de la condicionalidad. ${ }^{12}$

2) Con frecuencia los términos de la condicionalidad provocan problemas políticos al interior de los Estados: "Las reformas son vistas como el resultado de una imposición externa, el incentivo para llevarlas a cabo es producto de la dominación foránea del proceso de reforma”. ${ }^{13}$ En el caso de los países de Asia central, las elites políticas observan en ciertos criterios condicionados una potencial amenaza a su status quo, especialmente en las exigencias de una mayor democratización de los sistemas políticos, el respeto a los derechos humanos o la transparencia.

3) El cumplimiento de las normas condicionadas puede verse afectada negativamente por aspectos como la pobreza o la inestabilidad política de los Estados: “cuando las instituciones políticas se han colapsado — o se encuentran en tal proceso — no debe sorprender que el incentivo mágico de la condicionalidad ha sido debilitado". ${ }^{14}$

11 Ibidem, p. 208.

12 Checkel, Jeffrey T., op. cit., p. s/n.

13 Idem.

14 Idem. 
Como se mencionó anteriormente, organismos internacionales como la OTAN, la UE o el Consejo de Europa se han ocupado de incluir algún tipo de condicionalidad en los acuerdos con los terceros países que han pretendido realizar alguna adhesión a sus estructuras:

Las condiciones que estos imponen a los solicitantes como la reestructuración de las relaciones entre civiles y militares, el establecimiento del Estado de derecho o la creación de nuevas agencias defensoras de los derechos humanos van más allá del paquete estándar de condicionalidades del FMI y, de hecho, se entrometen en las atribuciones socio-políticas de esos Estados. ${ }^{15}$

Como antecedente histórico al uso de la condicionalidad por parte de la Comunidad Europea, puede mencionarse la firma de una "Declaración sobre derechos humanos y la política exterior" realizada en julio de 1986 por los Ministros de Relaciones Exteriores de la Comunidad Económica Europea (CEE) en la que se reconocía la protección de los derechos humanos como "una obligación legítima y continua, en la que se reconoce la conexión entre la democracia, el desarrollo y criticaba el gasto excesivo en defensa militar". ${ }^{16}$ La protección de los valores anteriores debía servirse de un conjunto de herramientas, entre las cuáles la condicionalidad tendría un papel fundamental, particularmente durante los posteriores procesos de ampliación realizados por la UE hacia Europa del Este; por su parte, la idea de transparentar (e incluso limitar) el gasto en defensa militar de los países que podrían recibir ayudas europeas residió en la consideración de que dicho gasto distraía otras prioridades como los programas sociales.

En el plano institucional, el uso de la condicionalidad se encuentra regulado por el primer pilar de la UE, es decir, en donde se sitúan las directivas básicas que orientan sus procesos de cooperación con el exterior, involucrando los actos legales y las competencias de sus instituciones. La Comunidad Europea definió el marco legal en el que la UE podía establecer relaciones de asistencia y cooperación para el desarrollo con terceros países en los artículos 177 al 181 del Tratado de la Unión

15 Idem.

16 Zanger, Sabine C., "Good Governance and European Aid. The Impact of Political Conditionality”, European Union Politics, vol. 1, núm. 3, 2000, p. 294. 
Europea (TUE) de 1992. ${ }^{17}$ Pero adicionalmente, la CEE había establecido previamente un conjunto de relaciones especiales con ciertos países que resultaban ser antiguas colonias de algunos estados miembros de la Comunidad: "En este contexto, de alguna forma la CEE/UE puede haber continuado con la influencia de los antiguos poderes coloniales". ${ }^{18}$ Sin embargo, estas relaciones especiales se sitúan en un nivel distinto a las relaciones de asistencia establecidas en el contexto del proceso de ampliación o las relaciones de donador de ayuda con otros grupos regionales.

Puede considerarse que el tipo de condicionalidad que ha aspirado a mantener la Comunidad Europea con los terceros países receptores de ayuda pertenece al rubro de la condicionalidad política: para Sabine Zanger, el concepto de condicionalidad política es producto de un proceso que lleva a considerar a los valores de la buena gobernanza como de validez universal, haciendo su promoción una obligación moral por parte de quienes compartan esos valores y cuenten con los recursos para proporcionar la ayuda: "En este contexto, la ayuda para el exterior se considera no solo una transferencia de dinero y recursos, sino también una transferencia de valores". ${ }^{19}$ De acuerdo a Zanger, la condicionalidad política se puede definir como una manera de promover el desarrollo económico en los países receptores ya que una mayor cercanía en sus relaciones y la estabilidad política puede fomentar las relaciones económicas: "A largo plazo, el fomento de los derechos humanos y la democracia puede incrementar los lazos comerciales entre el donador y el receptor”. ${ }^{20}$

17 Previamente al Tratado de la Unión Europea, la cooperación para el desarrollo con terceros países había estado regulada por los artículos 130 u al 130 y del Tratado Constitutivo de la Comunidad Europea. Cfr. Tratado Constitutivo de la Comunidad Europea, título XVII, http: / / europa.eu/abc/treaties/archives/es/estr6d17.htm.

18 Nyman-Metcalf, Katrin, "Influence through Assistance-the EU Assistance Programs", European Public Law, vol. 9, núm. 3, 2003, p. 427.

19 Zanger, Sabine C., op. cit., p. 297.

20 Idem. 

A. Los programas de asistencia técnica
a. El Programa TACIS

Como antecedente al establecimiento de relaciones entre los miembros de la UE y los países centroasiáticos, debe mencionarse el reconocimiento formal entre la Comunidad Económica Europea y el Consejo de Cooperación y Asistencia Económica Mutua (mejor conocido como Comecon) en 1988; posteriormente un "nuevo tipo de relaciones contractuales" entre la CEE y los países comunistas fue alcanzado mediante un Acuerdo de Comercio y Cooperación establecido en 1989 (basado en los artículos 133 y 308 del Tratado de la CEE), sin embargo dicho acuerdo perdió su vigencia tras la disolución del Comecon en junio de 1991. Con la disolución de la URSS en diciembre de 1991, los miembros de la nueva Comunidad de Estados Independientes (CEI) se vieron en la posibilidad de establecer acuerdos con otros actores internacionales (si bien el tratado de la CEI les impedía la facultad de establecer tratados de libre comercio con otras entidades ajenas a la propia Comunidad).

En el contexto de la entrada en vigor del Tratado de Maastricht en 1992, la Unión Europea comenzó a instrumentar una nueva aproximación de sus programas de ayuda hacia los países ex soviéticos, con el fin de apoyarlos para que iniciaran sus procesos de transición a economías de libre mercado. El desarrollo de los procesos de transición en los países ex comunistas llevó a que la UE diferenciara los procesos de cambio político sucedidos en la antigua URSS de su aproximación alrededor de la transición política hacia la democracia de los países ex comunistas de Europa del Este.

Tras la desaparición de la URSS, la Comunidad Europea aprobó la creación de un programa de asistencia técnica específico para los países pertenecientes a la nueva CEI, el cual se constituiría de manera similar al Programa Phare (creado en 1989 y acrónimo de Poland and Hungary: Assistance for Restructuring their Economies), es decir, el programa de asistencia orientado hacia los países de Europa del Este. ${ }^{21}$

21 Se debe mencionar que las repúblicas bálticas de Estonia, Letonia y Lituania fueron incluidas en el programa Phare, por lo que pudieron participar posteriormente en el proceso de ampliación de la UE. 
El programa TACIS se conformó como el esquema coordinador de ayuda de la UE hacia los países pertenecientes al espacio ex soviético, incluida Asia central, estableciéndose de esta forma una diferenciación entre el programa de ayuda Phare y la constitución del mencionado programa TACIS y posteriormente los PCA. ${ }^{22}$

En 1992 la Comisión Europea convocó a una cumbre con doce países ex soviéticos que previamente se habían integrado en el programa Tacis para concertar los planes de ayuda a instrumentarse durante los años subsiguientes: entonces se acordó que se extenderían los planes aprobados previamente a la desaparición de la URSS hasta 1993, para ser continuados posteriormente durante los periodos 1993-1995 y 1996 2000..$^{23}$ Durante los primeros años de operación del Programa Tacis pudo observarse una preferencia europea por enfatizar la colaboración en áreas técnicas sobre los asuntos políticos y de gobierno, una tendencia que fue compartida por los gobiernos centroasiáticos:

Por una parte los países de Asia central preferían obtener la asistencia con el propósito de fortalecer las instituciones administrativas, la atracción de las inversiones extranjeras, el mejoramiento de los sistemas educativos, el desarrollo del sector agropecuario y el cambio en sus regulaciones legales en lugar de hacerlo en áreas como la democratización o el respeto por los derechos humano, entre otras áreas políticas. ${ }^{24}$

Sin embargo, la orientación técnica del programa de ayuda fue modificada durante el segundo periodo de operación; es decir, los dos

22 El programa Phare había sido instaurado previamente a la Cumbre de Roma de 1991, pero el Consejo Europeo decidió crear un nuevo programa de asistencia específicamente para los países pertenecientes al espacio ex soviético: "La decisión se debió a la diferente naturaleza de las aproximaciones de cada miembro de la Comunidad hacia esas dos regiones de Europa del Este así como para discernir los requerimientos específicos del Estado soviético de una manera mas adecuada". Sodupe, Kepa y Benito, Eduardo, "The Evolution of the European Union's Tacis Programme, 1991-1996”, Journal of Communist Studies and Transition Politics, vol. 14, núm. 4, 1998, p. 52.

${ }^{23}$ Idem, p. 53.

${ }^{24}$ Efegil, Ertan, "Analysis of the EU's Central Asia Policy: from a Project-oriented Approach to a New Strategic Partnership”, The Turkish Yearbook of International Relations, Ankara, vol. 38, 2007, pp. 117-118. 
objetivos prioritarios del programa TACIS para el periodo 1996-2000 fueron en este orden: a) ayudar a los países receptores a concluir su transición hacia una economía de mercado; b) ayudar al desarrollo de las instituciones democráticas; hasta 2001 el programa TACIS se enfocó principalmente en cinco sectores: entrenamiento de recursos humanos, energía, transporte, industria y comercio y producción alimentaria. ${ }^{25}$

El programa TACIS se desarrolló tomando la experiencia de otros programas de ayuda europea hacia el Tercer Mundo; para Kepa Sodupe y Eduardo Benito la asistencia técnica europea dirigida a los países adheridos a TACIS fue negociada con base en lo que se puede denominar acuerdos de "primera y segunda generación de condicionalidad": "Los primeros, predominantes en los años ochenta, fueron principalmente de carácter económico, sujetos a los requerimientos para la introducción de políticas estructurales...”. ${ }^{26}$ "La condicionalidad de segunda generación, prevaleciente durante los años noventa, tendió a intervenir en asuntos de naturaleza esencialmente política, relacionándose con el respeto a las libertades políticas y los derechos humanos". ${ }^{27}$

La orientación del programa TACIS hacia la propagación del cambio político e institucional en los países ex soviéticos aumentó a mediados de los años noventa, pero en contraste a la difusión de las normas euro-

25 Ibidem, p. 117.

En 2000 el programa TACIS integraba a los siguientes países: Armenia, Azerbaiyán, Bielorrusia, Georgia, Kazajastán, Kirguistán, Moldavia, Mongolia (una excepción al no ser miembro de la CEI), Rusia, Tayikistán, Turkmenistán, Ucrania y Uzbekistán.

De acuerdo a información de la Comisión Europea, desde su puesta en operación hasta el año 1999 el programa TACIS había invertido 4226 millones de euros y se planeaba un presupuesto de 3, 138 millones de euros para los programas de ayuda durante el periodo 20002006. De acuerdo a la Comisión, el programa TACIS había cambiado durante su primera etapa de operación para convertirse en "algo mas que un programa de asistencia técnica": "TACIS se enfoca en apoyar a los países socios en el desarrollo de sus economías de mercado y en el fortalecimiento de sus fundamentos democráticos y jurídicos”. Comisión Europea, Tacis. The European Union and the Countries of Eastern Europe, the Caucasus and Central Asia, Bruselas, 2000, p. 2.

26 "Al respecto, las autoridades de la Comunidad insistían que los gobiernos beneficiarios de las ayudas deberían adoptar una actitud favorable hacia las reformas. Ellas también enfatizaban la necesidad de restringir la asistencia hacia sectores y áreas geográficas en donde ya habían sido introducidas medidas específicas diseñadas para promover el cambio estructural”. Sodupe, Kepa y Benito, Eduardo, op. cit., p. 53.

27 Idem. 
peas, los países centroasiáticos mantuvieron sus preferencias en obtener asistencia para fortalecer a sus instituciones administrativas y jurídicas (por encima de la democratización), atraer inversiones extranjeras (en una variedad de sectores, no sólo energéticos), así como para mejorar sus sistemas educativos y el desarrollo agrario. ${ }^{28}$ Los límites operativos del programa TACIS residían en el carácter condicionado de la ayuda, algo que aumentó en los años siguientes, en contraste a los PCA los cuales incluían un compromiso bilateral formal a la hora de recibir la ayuda pero sin la rigidez del programa TACIS. Igualmente la planeación de la asistencia técnica del programa TACIS podía considerarse un producto formulado unilateralmente por las autoridades de la Comunidad Europea, sin mucha participación previa de las autoridades de los países receptores. En 2007 el Programa TACIS fue sustituido por el Instrumento de Cooperación para el Desarrollo (Development Cooperation Instrument o DCI).

De la misma manera, otro factor que puede mencionarse para explicar los pocos resultados del programa TACIS concierne a la ausencia de un país europeo que sirviera tanto como un enlace diplomático con los países centroasiáticos y como un coordinador de la agenda; en algunos esquemas de relaciones de la UE con regiones del tercer mundo, ciertos países europeos (especialmente algunos países excoloniales) han podido desarrollar esta función: pueden mencionarse como ejemplos la relación privilegiada de Francia con ciertos países de África, al Reino Unido con su agrupación de antiguas colonias (la Commonweatlh) o el caso de España en su relación histórica con los países de Latinoamérica. Sin embargo, en el caso de Asia central no existió un país europeo que asumiera el papel de coordinador de la agenda con una región que, debe tomarse en cuenta, nunca fue colonizada por un país europeo occidental: de la misma manera, la existencia de otras regiones del tercer mundo que resultaban prioritarias para ciertos actores clave del espacio europeo fue también un factor que impidió que se conformara una visión integrada en la UE sobre la región centroasiática. ${ }^{29}$ Hasta el momento no se ha conformado un esquema de diálogo entre regiones como en el caso de las relaciones euro-africanas o euro-latinomericanas.

28 Efegil, Ertan, op. cit., p. 118.

29 Lamoulin, Marat, “Central Asia and the European Union”, en Rumer, Boris (ed.), Central Asia:A Gathering Storm?, Armonk, M. E. Sharpe, 2002, p 209. 
b. Proyectos en materia de transportes y energía

El Plan de Acción de la Comisión Europea ha sido el responsable de impulsar algunos programas de cooperación de los cuáles resaltan el programa TRACECA (Transport Corridor Europe-Caucasus-Asia) en materia de transportes y el programa INOGATE (Interstate Oil and Gas Transport to Europe) en el área de la energía.

Desde 1993 la Comisión Europea ha financiado un programa intergubernamental para el establecimiento de redes de transporte con el fin de incentivar el comercio mediante la construcción de un corredor comercial Cáucaso-Europa-Asia central denominado TRACECA; en 1998 los involucrados firmaron un acuerdo multilateral en Bakú con el fin de comprometerse al reestablecimiento de una "Ruta de la Seda" y en el año 2000 el proyecto TRACECA se transformó en una comisión intergubernamental bajo el reconocimiento de la ONU. ${ }^{30}$

Por otra parte, en 1995 la UE inició un programa para la explotación y transportación de los recursos energéticos de los países ribereños del Mar Negro y el Caspio hacia Europa comúnmente denominado INOGATE:

El programa se enfocó en cuatro áreas prioritarias: un mejoramiento de la seguridad energética; la promoción de la convergencia entre los mercados energéticos de los Estados miembros sobre la base de los principios del marcado de energía interno de la UE; el apoyo al desarrollo de la energía sustentable; y la atracción de inversiones en proyectos de energía de interés común y regional. ${ }^{31}$

Sin embargo, los programas como TRACECA e INOGATE no recibieron una continuidad adecuada por lo menos hasta después de la coyuntura internacional presentada por los atentados del 11 de septiembre de 2001 en contra de Estados Unidos, debido a que el presupuesto de la asistencia europea en los años previos fue reducido hasta en dos ocasiones: fue necesaria la coyuntura de la guerra contra los talibanes en Afganistán para que la importancia de la región se incrementara y el

30 Yazdani, Enayatollah, "The European Union and Central Asia”, International Studies, vol. 45, núm. 3, 2008, p. 250.

31 Ibidem. p. 249. 
monto de la ayuda fuera restaurado a los niveles previos. ${ }^{32}$ Debido a la importancia alcanzada en materia de la seguridad energética, el proyecto INOGATE comenzó a ser financiado por el Programa de Iniciativas de la Política Europea de Vecindad (PEV) a partir de 2007.

\section{Los Acuerdos de Asociación y Cooperación (PCAs)}

A lo largo del desarrollo institucional de la UE se ha observado la formulación de dos tipos de asociaciones, en tanto figuras jurídicas, establecidas entre la UE y un tercer país: en un primer caso, los acuerdos de asociación preparatorios para la adhesión del tercer país a la UE (los países admitidos en el proceso de ampliación pueden establecer una relación "privilegiada" con la UE en cuyo transcurso realizan un conjunto de reformas internas, con el fin de adecuarse a las directivas comunitarias); en un segundo caso, con una base jurídica más ambigua, se han establecido acuerdos de asociación con terceros países con el fin de establecer relaciones de cooperación en un sentido amplio, así como programas de ayuda orientados al desarrollo económico y social del país asociado. Los primeros acuerdos de asociación para el desarrollo entre la Comunidad Europea y un tercer país pueden remontarse hasta el inicio de la década de 1960: dichos acuerdos se orientaron tanto a los países del norte de África ribereños con el Mediterráneo como a las ex colonias europeas ubicadas en África, el Caribe y el Pacífico (los países ACP). Con el tiempo los acuerdos de asociación han dado origen a procesos de cooperación más complejos como el llamado "Proceso Barcelona” en el Mediterráneo y al Acuerdo de Cotonou en el caso de los países ACP. ${ }^{33}$

32 Matveeva, Anna, "EU Stakes in Central Asia”, Chaillot Paper núm. 91, París, EUISS, 2006, p. 87.

33 Moreau-Defarges define al concepto de asociación como "el esfuerzo de organización de las relaciones estables entre dos o mas entidades (estados o agrupaciones regionales)”. Un acuerdo de asociación contiene al menos tres características: a) la adhesión a un mínimo de principios comunes de las partes permanentes con el fin de reconocer un interés superior o por encima de los intereses particulares; $b$ ) la alusión a la condición de igualdad entre los socios, al menos en el discurso; c) la intención de los socios por avanzar mas allá de un simple equilibrio de fuerzas con el fin de edificar un bien común. 
La característica jurídica común de los anteriores acuerdos de asociación y sus correspondientes procesos de diálogo y cooperación radica en que tuvieron como base legal a los artículos 300 y 310 del Tratado de la Unión Europea: una condición jurídica que se estableció no obstante la heterogeneidad de los participantes así como sus intereses en establecer un diálogo con la Comunidad Europea y los diferentes contextos políticos en los que se sitúan. ${ }^{34}$ Tanto la ampliación como la cooperación con fines de desarrollo se habrían de basar en “... un régimen preferencial fundamentado sobre el principio de no reciprocidad y la emergencia de una cooperación que dependerá con el paso de los años de una dimensión más política”. ${ }^{35}$

Los cambios en el sistema internacional tras el final de los regímenes comunistas en Europa oriental en 1989, así como la disolución de la Unión Soviética en 1991, determinaron, por razones obvias, la apari-

Sobre la relación entre la aparición de las asociaciones en el sistema internacional con los procesos de globalización y regionalización deben considerarse tres características: 1) las asociaciones son producto de la dinámica doble de globalización y regionalización del sistema internacional; 2) las asociaciones pueden considerarse un medio de conciliación entre los procesos de globalización y regionalización; 3) desde la perspectiva de un acuerdo de asociación, establecer cuáles son los equilibrios posibles entre la globalización y la regionalización. Moreau-Defarges, Philippe, "Partenariat, mondialisation et régionalisation", en Labouz, Marie-Françoise (ed.), Le Partenariat de l'Union européenne avec les pays tiers, conflits et convergences, Bruselas, Bruylant, 2000, pp. 39 y 40

34 Esta legislación estuvo vigente hasta la entrada en vigor del Tratado de Lisboa el 1o. de diciembre de 2009.

De acuerdo al apartado 6 del artículo 300 del TUE la viabilidad de un acuerdo internacional debe ser dictaminada por el Tribunal de Justicia Europeo: "El Parlamento Europeo, el Consejo, la Comisión o un Estado miembro podrán solicitar el dictamen del Tribunal de Justicia sobre la compatibilidad de cualquier acuerdo previsto con las disposiciones del presente Tratado. Cuando el dictamen del Tribunal de Justicia sea negativo, el acuerdo sólo podrá entrar en vigor en las condiciones establecidas en el artículo 48 del Tratado de la Unión Europea". Cfr. Diario Oficial de la Unión Europea, 2006, Tratado de la Unión Europea, Bruselas, p. CE 321 E/177, http://eur-lex.europa.eu/LexUriServ/LexUriServ.do?uri=OJ:C:2006:321 E:00 01:0331:es:pdf.

Por su parte, el artículo 310 establece: "La Comunidad podrá celebrar con uno o varios Estados o con organizaciones internacionales acuerdos que establezcan una asociación que entrañe derechos y obligaciones recíprocos, acciones comunes y procedimientos particulares". Cfr. ibidem, p. CE $321 \mathrm{E} / 179$.

35 Gaudissart, Marc-André, "Réflexions sur la nature et la portée du concept d'association à la lumière de sa mise en oeuvre”, en Tchakaloff, Marie -France (ed.), Le concept d'association dans les accords passés par la Communauté: essai de clarification, Bruselas, Bruylant, 1999, p. 15. 
ción de una mayor variedad de acuerdos con terceros países; dichos acuerdos asociativos han sido enfocados en cada caso particular, lo que también ha estado determinado por otros procesos internos de la UE como el proceso de ampliación de 2004 así como por otras coyunturas internacionales. ${ }^{36}$

Para Gaudissart de manera ideal el Acuerdo de Asociación y Cooperación ha sido articulado en una triple composición de objetivos básicos: busca conformar un espacio de diálogo y concertación política, una liberalización con el objetivo de aumentar los intercambios comerciales y un reforzamiento para las nuevas líneas de cooperación acordadas por los socios. ${ }^{37}$ Por su parte, los PCA establecidos con cada uno de los miembros de la CEI se constituyeron como "el esquema contractual de las relaciones exteriores de la UE con la antigua URSS”. En primera instancia los nuevos acuerdos de asociación buscaban crear un cambio político y legal buscando integrar "una nueva dimensión organizacional a las relaciones entre los nuevos socios". ${ }^{38}$

El PCA era un acuerdo constituido para definir los compromisos de los socios para fortalecer sus acercamientos, aunque desde el lado europeo las obligaciones del socio se orientaban, de acuerdo a los principios de la condicionalidad, al establecimiento de sistemas políticos democráticos y la implantación de economías de libre mercado:

El PCA es un acuerdo mixto establecido entre la Comunidad Europea, sus Estados miembros y algunos terceros países de manera individual, en este caso ex miembros de la Unión Soviética. El PCA se adaptaba a las necesidades de cada país en específico aunque todos los PCA poseen elementos en común y se estructuraban

${ }^{36}$ Idem. Sin embargo, la clasificación jurídica de los artículos ni la repartición de sus competencias o la separación de sus bases jurídicas evitan el carácter complejo y ambiguo de los acuerdos de asociación y que "cada vez sea mas difícil definir así como caracterizar a la asociación” a la vez que "El contenido y el ámbito de aplicación de la asociación varían totalmente de un acuerdo a otro, de acuerdo a la proximidad económica de los socios, la mutua apertura de sus sectores o la ambiciones políticas". Tchakaloff, Marie-France, "Introduction”, en Tchakaloff, Marie-France (ed.), Le concept d'association dans les accords passés par la Communauté: essai de clarification, Bruselas, Bruylant, 1999, pp. viii-ix.

37 Gaudissart, Marc-André, op. cit., p. 31.

38 Hillion, Christophe, "Institutional Aspects of the Partnership between the European Union and the Newly Independent States of the Former Soviet Union: Case Studies of Russia and Ukraine”, Common Market Law Review, vol. 37, 2000, pp. 1213-1215. 
de manera similar. El PCA otorga un esquema para el desarrollo de las relaciones entre los socios incluyendo un diálogo político, asistencia y relaciones comerciales no discriminatorias y provee un proceso de diálogo político formalizado de manera regular. El PCA expresa el compromiso de los socios para desarrollar un entendimiento más cercano para la cooperación en el fortalecimiento de las instituciones democráticas y una economía de mercado en los países de la CEI. ${ }^{39}$

El PCA incluía aspectos de cooperación legal como comercio, propiedad intelectual, inversiones, impuestos y aduanas.

La diferencia legal entre los acuerdos con los países de Europa del Este y los PCA radicaba en que los primeros eran acuerdos de asociación basados en el establecimiento de una relación privilegiada, incluyendo la posibilidad de su participación en el sistema legal de la organización, lo que se conseguiría mediante el proceso de ampliación de la UE.

Sin embargo, desde el punto de vista de Christophe Hillion a la diferenciación establecida entre los países de Europa del Este y los miembros de la CEI se agregó una subdivisión entre los países surgidos de la desaparición de la URSS, particularmente una distinción entre los acuerdos que establecería la UE con Bielorrusia, Moldavia, Rusia y Ucrania, por una parte, en comparación con los acuerdos constituidos con los países del Cáucaso y Asia central: los PCA acordados con el primer grupo de países "contenía una cláusula evolutiva, ausente en los otros PCA, mediante la cual los socios se comprometen a considerar en una etapa posterior la creación de un área de libre comercio entre ellos". ${ }^{40}$ Por lo anterior, los PCA acordados con Asia central poseen un esquema institucional menos desarrollado que los establecidos con $\mathrm{Ru}$ sia o con Ucrania.

El TUE no otorgaba una base legal específica a los PCA. Los PCA ilustran que la relaciones externas de la Comunidad se basarían en los principios de la Política Exterior y de Seguridad Común (PESC) "en línea con los requerimientos del artículo 3 del TUE": el concepto de asociación aplicado en el contexto de las relaciones entre la UE con los miembros de la CEI “... ha estado conectado con la Unión como un todo. Esto constituye un ejemplo de lo que podría ser visto como una acción

39 Nyman-Metcalf, Katrin, op. cit., p. 435.

40 Hillion, Christophe, op. cit., p. 1216. 
exterior mixta de la UE con una dimensión que entrecruza los pilares". ${ }^{41}$ Dicho entrecruzamiento de las áreas reservadas a los tres pilares de la UE se ha debido a que todas las áreas tuvieron que ser incluidas en una misma estructura de diálogo.

Al formar parte del sistema legal-institucional de la UE, los PCA han actuado como las instancias legales encargadas de especificar el desarrollo de las relaciones económicas y políticas entre la UE y Asia central. Los primeros países en negociar un PCA con la UE fueron Kazajstán y Kirguistán en 1992, con unos acuerdos concluidos en 1996. Por su parte, el acuerdo con Uzbekistán fue concluido en 1999.

Sin embargo, existen dos casos particulares: Turkmenistán negoció un PCA concluido también en 1998, pero que nunca ha entrado en funcionamiento debido a la situación de los derechos humanos en ese país. En un caso distinto, la UE inició negociaciones para establecer un PCA con Tayikistán, pero la guerra civil en ese país retrasó la firma del acuerdo: en 2004 se culminó su negociación y el acuerdo entró en funcionamiento hasta 2010:42 "los PCAs formalizaron las relaciones bilaterales entre la UE y los países asociados individualmente y otorgaron a los nuevos países independientes una plataforma común para fijar asuntos políticos y económicos a tratar, así como otros de importancia común”; sin embargo, los PCA no significaban una aproximación para una futura admisión en la UE y contenían una cláusula de condicionalidad que podía anularlo: "El acuerdo podía ser cancelado si existían violaciones graves a los derechos humanos en el país socio". ${ }^{43}$

Debido a lo anterior, la condicionalidad incluida en la negociación de los PCA tenía una naturaleza positiva. De la misma manera, los PCA establecieron un conjunto de "formatos institucionales" como un Consejo de Cooperación (encuentros ministeriales organizados anualmente por la Presidencia del Consejo Europeo), Comités de Cooperación bajo la responsabilidad de la Comisión y un Consejo de Cooperación Parlamentaria bajo responsabilidad del Parlamento Europeo. ${ }^{44}$

41 Ibidem, p. 1219.

42 Matveeva, Anna, op. cit., p. 85.

43 Yazdani, Enayatollah, op. cit., p. 249.

${ }^{44}$ Matveeva, Anna, op. cit., p. 85. 
Los PCA consistían de tres secciones: para el diálogo político, la cooperación bilateral y las relaciones económicas y comerciales: específicamente, la mayor parte de las actividades que componían la agenda se centraban en asuntos económico-comerciales aunque predominando un principio de no reciprocidad dada la naturaleza asimétrica de la relación. En lo referente al diálogo político, si bien en los PCA se reproducía la retórica alrededor de la buena gobernanza, no quedaban claros los mecanismos que llevarían a la aceptación de los valores europeos por parte de los interlocutores centroasiáticos:

Los documentos de los PCA exhibían poco más que la ambición por apoyar un cambio político y fortalecer el enlace entre los países con la comunidad democrática a través del diálogo político... El diálogo político fue planeado en los niveles ministerial y parlamentario con una frecuencia más bien baja. ${ }^{45}$

Puede considerarse que los PCA establecidos con los países centroasiáticos en ocasiones no trascendieron el carácter simbólico que encarnaron al ser un reconocimiento europeo de la independencia y soberanía de los nuevos países de Asia central; más allá del carácter diplomático de los PCA, durante la primera mitad de los años noventa los países de Asia central se mantuvieron como una preocupación periférica para Europa occidental, por lo que transcurrió alrededor de una década para que la UE desarrollara una "visión estratégica" para la región.

4. La evolución de la relación UE-Asia central durante los años noventa:

la construcción de una relación asimétrica

Fue hasta la segunda mitad de los años noventa que Asia central atrajo la atención europea gracias a la previa puesta en operación de la PESC, a partir de 1993, así como por el desarrollo de ciertos procesos políticos

45 Hoffmann, Katharina, "The EU in Central Asia: Successful Good Governance Promotion?”, ThirdWorld Quarterly, vol. 31, núm. 1, 2010, p. 94.

Como parte de su flexibilidad, el diálogo político puede llevarse a cabo como parte de las estructuras del PCA, o de manera externa al acuerdo, lo que indica "el grado de flexibilidad de la asociación, algo incluso necesario considerando los límites de los mecanismos para la resolución de conflictos que posee”. Hillion, Christophe, op. cit. p. 1222. 
al interior de los países centroasiáticos como la conservación del status quo de las elites políticas de la región que continuaron en el poder tras la desaparición de la URSS, la convicción de que era preferible que desarrollaran sistemas políticos pluralistas y el rechazo a la emergencia de algún régimen islámico en la región con una orientación anti occidental; a partir de 1995 la parte europea inició un reconocimiento del potencial de los recursos energéticos de la región para su explotación a la vez que los países centroasiáticos visualizaron a los países europeos como un "mercado confiable" para su producción de petróleo y gas. ${ }^{46}$

A mediados de los años noventa, Asia central era percibida en Estados Unidos, así como entre algunos miembros de la UE (especialmente Alemania o Reino Unido), como un espacio que podría sufrir el riesgo de atravesar por alguna desestabilización que provocara un enfrentamiento intrarregional entre los nuevos países, de manera análoga a lo que ocurría al mismo tiempo en los Balcanes (entonces la mayor preocupación para las autoridades europeas en materia de seguridad); por la razón anterior, la UE se enfocó en aplicar programas de asistencia que contribuyeran al fortalecimiento de las independencias nacionales de esos países, se mantuviera un control sobre la emergencia del Islam político y se llegara a acuerdos sobre el control de armas. En este sentido, los PCA pudieron funcionar como acuerdos ad hoc con una agenda basada en temas específicos y con un grado de condicionalidad menor en comparación al Programa TACIS aunque "sin un esquema político tangible sobre el cual trabajar". ${ }^{47}$

Para Marat Lamaulin en esta primera etapa la cuestión de la seguridad geopolítica comenzó a asumir cierta importancia para las autoridades europeas, pues si bien la cuestión energética resultaba relevante, en la segunda mitad de los años noventa los países centroasiáticos Comenzaron a adquirir una alta significación al representar una especie de territorio de frontera, es decir:

... un bastión de separación para Rusia y Europa del mundo islámico. La política europea no debía consistir tanto en crear una nueva "Ruta de la Seda" sino en

46 Yazdani, Enayatollah, op. cit., pp. 247-248.

47 Matveeva, Anna, op. cit., p. 85. 
conformar un puente cultural o incluso una "zona pivote” entre el norte industrializado y el sur subdesarrollado. ${ }^{48}$

Las percepciones anteriores, sostenidas por las autoridades europeas, se adhieren ideológicamente a los postulados que sostienen que los regímenes democráticos son necesariamente más pacíficos y estables; sin embargo, un argumento afirmando que la ayuda otorgada desde el exterior debería contribuir a la seguridad del donador de esa ayuda corresponde a una perspectiva neorrealista:

Desde este punto de vista, la ayuda puede incrementar la seguridad del donador en la escena internacional cuando es usada para difundir la democracia, impulsar el respeto de los derechos humanos y desanimar el gasto en defensa. ${ }^{49}$

Al mismo tiempo la perspectiva anterior era un reflejo de los límites de la capacidad de actuación europea para intervenir en la región centroasiática, más allá de los programas de ayuda condicionada.

Un proyecto diseñado para las necesidades de seguridad de la UE en Asia central sólo podría alcanzarse mediante el desarrollo de mecanismos de cooperación y diálogo con la región apoyados en una diplomacia a la que podría denominarse como poder blando dada la incapacidad europea por desarrollar estrategias de defensa o intervención militar de manera autónoma a la OTAN. La UE trató de instrumentar sus propios mecanismos para alcanzar cierta influencia política entre los países de Asia central pero de una manera no siempre efectiva debido a que la condicionalidad de la asistencia técnica, en tanto exigencia de democratización de los procesos políticos, generó mucha renuencia entre las elites políticas de los países involucrados: en lugar de una intervención directa en la región, la UE se ocupó de crear una idea particular sobre Asia central de acuerdo a las coyunturas del momento.

Además de los diferentes intereses de los países miembros en la región, la falta de una política unificada por parte de la UE hacia la cuenca del Caspio y Asia central también residió en distintas prioridades políticas al interior de sus instituciones, particularmente en el tandem Co-

48 Lamoulin, Marat, op. cit., p. 212.

49 Zanger, Sabine C., op. cit., p. 295. 
misión Europea-Consejo Europeo: mientras que el Consejo recomendó un mayor énfasis en la inversión de capital europeo en la producción de energéticos (y el diseño de las futuras rutas de oleoductos para su transportación), la Comisión diseñó una agenda política basada en las normativas sobre la buena gobernanza (orientada hacia la democratización, la transición económica, la sustentabilidad ambiental de las reformas, las inversiones europeas en la región y el diálogo político). ${ }^{50}$ Lo anterior era reflejo de la falta de consistencia de la aproximación europea: si bien las instituciones de la UE no mostraban la voluntad política para desarrollar un acercamiento en términos de igualdad con los países centroasiáticos (como entonces ocurría hacia los países de Asia del Este), sí diferían en la manera como debía expresarse la relación asimétrica que se mantendría con Asia central.

\section{El aparato institucional de la UE y Asia central: el Consejo Europeo y el Representante Especial}

Además de los mecanismos de ayuda coordinados por la Comisión Europea, en tiempo más reciente el Consejo Europeo y su Presidencia rotatoria también han mostrado interés por tener una presencia en Asia central mediante la creación de la figura de un funcionario en misión específica para la región, denominado Representante Especial para Asia central (Special Representative for Central Asia o EUSRCA). Como una iniciativa para tratar de aumentar su presencia en la región, el Consejo Europeo nombró a un Representante Especial para Asia central en 2005, con el fin de establecer un canal de comunicación directo de alto nivel con las dirigencias de los países de la región y con el fin de "jugar un papel más activo en la región, profundizar el diálogo político con actores relevantes y para coordinar sus compromisos con la región de una manera más firme en el nivel político". ${ }^{51}$

50 Lamoulin, Marat, op. cit., p. 214.

${ }^{51}$ Schmitz, Andrea, "Efficiency and its Cost: The "Strategy for a New Partnership" with Central Asia”, en Kietz, Daniela y Pertez, Volker (ed.), The Potential of the Council Presidency: An Analisys of the Germany's Chairmanship of the EU, SWP Research Paper, Berlín, Stiftung Wissenschaft und Politik, 2008, p. 72. 
El primer representante especial para Asia central fue el diplomático Jan Kubis, quien estuvo al frente del cargo hasta 2006. En octubre de 2006 fue designado Pierre Morel, quien ocupa el cargo hasta el momento; sin embargo, "la UE siguió careciendo de una visión estratégica coherente y comprensiva para Asia central...”. ${ }^{52}$ El representante especial se encuentra orientado a proteger los intereses de los países miembros y su trabajo pone una mayor atención a las cuestiones concernientes a la protección de los derechos humanos y las actividades de Organizaciones No Gubernamentales promotoras de la democracia en la región. Sin embargo, hasta el momento no se han realizado cumbres entre la Presidencia del Consejo Europeo y algún país centroasiático y si bien la Presidencia ha asumido un presencia cada vez más significativa en asuntos relacionados con la región (no obstante que los países de Asia central no han contado con un lobby en Bruselas), el aparato institucional que ha funcionado para mantener un contacto más o menos bilateral entre el Consejo y las autoridades centroasiáticas ha sido el propio representante especial. Cabe mencionar que este último ha contado con unas oficinas centrales en Bruselas, algo que para Matveeva puede significar una "activación de la Política Europea de Seguridad y Defensa (PESD)”. ${ }^{53}$

\section{LOS COMUNICADOS ESTRATÉGICOS SOBRE ASIA CENTRAL}

A partir del año 2000 inició el primer proyecto europeo concerniente sobre cuestiones de seguridad en Asia central con el establecimiento de un Plan de Acción para luchar contra el narcotráfico proveniente de la región para el periodo 2000-2004. El Plan de Acción cubría las siguientes áreas: información; acciones para la reducción de la demanda; acciones en la reducción del tráfico de drogas; acciones en el nivel internacional, y coordinación..$^{54}$ Sin embargo, los atentados terroristas de

52 Shao Yuqun, "The EU's Central Asia Policy and its Implications for China”, Discussion Paper núm. 9, Bonn, Deutsches Institut für Entwicklungspolitik, 2008, p. 4.

53 Matveeva, Anna, op. cit., p. 92.

54 Yazdani, Enayatollah, op. cit., p. 251. 
2001 cambiaron las prioridades sobre cuestiones de seguridad en Asia central, por lo que las instituciones europeas decidieron integrar sus objetivos hacia la región centroasiática mediante un programa comprensivo denominado "Comunicado Estratégico", el primero de los cuales tendría una duración de cuatro años comprendiendo el periodo 2002-2006. ${ }^{55}$

\section{El Comunicado Estratégico sobre Asia Central 2002-2006}

El nuevo reconocimiento de la importancia de la región para la UE ha llevado a la formulación gradual de una mayor cantidad de programas de ayuda económica. El primer paso fue la formulación del documento estratégico para Asia central denominado Central Asian Regional Cooperation Program 2002-2006:

Esta estrategia buscaba mejorar los procesos democráticos, el respeto a los derechos humanos así como asistir a Asia central en la transición hacia una economía de mercado. Más aun, la UE deseaba contribuir con un incremento de la seguridad y a la eliminación de fuentes de tensión política y social, así como crear un mejor ambiente para el comercio y la inversión. La UE asignó 150 millones de euros del presupuesto del programa Tacis para instrumentar esta estrategia sobre un periodo de tres años. ${ }^{56}$

55 Los límites de la participación de la UE en las cuestiones de seguridad centroasiáticas comenzaron a quedar en evidencia desde 1999, cuando grupos extremistas realizaron ataques armados a Kirguistán, Tayikistán y Uzbekistán; entonces el discurso del presidente kirguisio Alskar Akayev, amenazado por los grupos islámicos, quien presentaba a su país como un "oasis" de la democracia en Asia central, tenía cierta credibilidad entre los funcionarios europeos. Significativamente las actividades de los extremistas en 1999 estimularon una mayor cohesión del entonces Grupo de Shanghai (la futura Organización de Cooperación de Shanghai, creada en 2001, a la que también se adhirió Uzbekistán por razones de seguridad). Desde el punto de vista europeo, una consecuencia de la amenaza extremista a la seguridad de los miembros de la CEI podría estimular la creación de un bloque se países que buscaba alejarse de la esfera de influencia de Rusia: "Europa consideró a estos acontecimientos como la coyuntura que iniciaba de la emergencia de dos bloques en la CEI: uno encabezado por Rusia en el marco del Tratado de Seguridad Colectiva de la CEI y otro conformado por cinco países, orientado hacia Occidente (el Grupo GUUAM: Georgia, Ucrania, Uzbekistán, Azerbaiyán y Moldavia). La oposición entre ambos bloques emergió claramente después de la cumbre de la OTAN de 1999, cuando Washington animó la formación de un grupo anti ruso al interior de la CEI”. Lamoulin, Marat, op. cit., p. 229.

56 Hoffmann, Katharina, op. cit., p. 95. 
La agenda del Programa TACIS fue incluida en la Estrategia de 20022006, con el fin de continuar con los mecanismos de asistencia desarrollados por la Comisión: "El programa TACIS fue desarrollado con base a los Programas de Acción anuales estableciendo áreas de intervención y proyectos de actividades concretos". ${ }^{57}$

Durante el periodo que duró la estrategia 2002-2006 se modificaron nuevamente las concepciones europeas sobre Asia central, ahora debido a dos procesos del proyecto de integración: la instrumentación de la Política Europea de Vecindad (PEV) en 2003 y la culminación del proceso de ampliación hacia Europa del Este en 2004. Los procesos anteriores atrajeron un nuevo conjunto de criterios hacia los países centroasiáticos, quienes comenzaron a ser clasificados como parte de una periferia adyacente a los países del Cáucaso que formalmente habían sido incluidos en la PEV como Armenia, Azerbaiyán o Georgia. Lo anterior significó que Asia central se convertiría en un "vecino de la vecindad europea", algo que fue reconocido oficialmente en la estrategia europea para la región formulada para el periodo 2007-2013:

Tanto la ampliación de la Unión como la nueva Política de Vecindad de la UE tienen implicaciones fundamentales para la naturaleza de las relaciones entre la UE y los Estados de Asia central y no puede dejar de reforzar los vínculos bilaterales. Estos últimos se han convertido esencialmente en "vecinos del vecindario europeo" debido a su ubicación geográfica y por sus sólidas relaciones económicas, políticas y culturales con los países cubiertos con las nuevas políticas de la UE hacia los países de Europa del Este. ${ }^{58}$

Igualmente, la reorganización de los instrumentos de ayuda resultante de la ampliación sirvió para enfatizar que los países de Asia central permanecerían fuera de la PEV, reafirmando un punto de vista europeo sobre la imposibilidad de que dichos países pudieran unirse a la UE en el futuro (aunque las aspiraciones de los países centroasiáticos al respecto fueran reales o no):

57 Shao Yuqun, op. cit. p. 3.

58 Comisión Europea/Consejo Europeo, Regional Strategy Paper for Assistance to Central Asia 2007-2013,Bruselas,2007,pp.6y 7,http: / / www.eeas.europa.eu/central_asia/rsp/07_13_en.pdf. 
Esta reorganización llevó a cabo un entendimiento implícito de que los prospectos para ser miembros de la UE no incluirían a Asia central. Sólo Kazajstán mostró su decepción al ser agrupado con países necesitados de asistencia para el desarrollo, mientras que otros países se resignaron a esta situación. ${ }^{59}$

\section{El Comunicado Estratégico sobre Asia central de 2007}

La última etapa de la política exterior de la UE hacia los países de Asia central se ha enfocado sobre las directivas contenidas en el comunicado Regional Strategy Paper for Assistance to Central Asia 2007-2013, el cual ha tratado de conformar la base de una "nueva estrategia" en las relaciones euro-centroasiáticas. La iniciativa por una nueva estrategia en las relaciones fue impulsada fundamentalmente por Alemania durante la Presidencia del Consejo Europeo que encabezó este país durante el primer semestre de 2007.

Un factor que llevó a la Presidencia alemana a formular una nueva estrategia en 2007 fue que la Estrategia de Asistencia para Asia central, formulada por la Comisión Europea en octubre de 2002, concluiría a finales de 2006: "De tal manera que el Consejo de la Presidencia Europea podría hacer uso de ideas relevantes y sugerencias por parte de la Comisión”. ${ }^{60}$ De esta manera la nueva estrategia podría ser considerada como una extensión de la renovada Estrategia de Asistencia, adoptada por la Comisión Europea en abril de 2007; la Presidencia alemana del Consejo se encontró con la coyuntura de que finalizaría el programa de asistencia de la Comisión Europea e impulsó la formulación de una nueva Estrategia para Asia central con el fin de integrar, a su propio proyecto, los resultados de la nueva Estrategia de Asistencia que adoptaría la Comisión. El resultado fue una mayor participación de la Presidencia del Consejo en las labores de la Comisión, de acuerdo a los planes y prioridades de Alemania.

La iniciativa por presentar una nueva estrategia hacia los países de Asia central puede considerarse un proyecto prioritario de la agenda de política exterior coordinada por la Presidencia alemana y para ello se integró una Troika en el esquema institucional de la PESC: dicha Troika fue con-

59 Matveeva, Anna, op. cit. p. 87.

60 Schmitz, Andrea, op. cit. p. 74. 
formada por la Presidencia alemana, el representante especial para Asia central y la Comisaria para Asuntos Exteriores de la UE (cargo ocupado por Benita Ferrero-Waldner); el trabajo de la Troika fue especialmente relevante en los contactos realizados con los países de la región para el desarrollo de la Estrategia de 2007. ${ }^{61}$ Por su parte, la Comisión Europea, quien es responsable en la instrumentación de los fondos y de las relaciones de la Comunidad con los países terceros, tuvo que transmitir parte de sus competencias al representante especial.

La expectativas sobre la nueva estrategia fueron muchas en el momento de su formulación y, de acuerdo a Schmitz, la Presidencia alemana consideró a su proyecto como un "éxito compartido" por las instancias que colaboraron en su formulación: la Presidencia del Consejo, el Alto Representante de la PESC, el Secretariado del Consejo Europeo y la Comisión Europea; igualmente en el nivel institucional, la Estrategia de 2007 puede considerarse también "una extensión de la Estrategia de Asistencia de la Comisión Europea”. ${ }^{62}$ Para Schmitz, la fuerte labor de coordinación llevada a cabo por la Presidencia alemana se debió a dos factores: en primer lugar, debido a las críticas recibidas por los programas y proyectos formulados por la Comisión Europea hacia la región, los cuáles habían sido señalados por ser fragmentados, incoherentes e infectivos, así como necesitados por dotarse conjuntamente de una coherencia conceptual; el segundo factor se debió a la "indiferencia mostrada por los Estados miembros” de la UE, quienes concibieron a la agenda con Asia central como algo de "importancia secundaria" y "no consideran a los Estados de Asia central primeramente como un objeto de cooperación europea conjunta, sino más bien como socios bilaterales". ${ }^{63}$

Por otra parte, la nueva estrategia de 2007 representó un cambio en la promoción de los valores de la buena gobernanza en la región; la estrategia se dividió en siete áreas de cooperación: en primer lugar, en una dimensión que integra a la economía con temas relacionados con la seguridad, aparecen áreas como "desarrollo económico", "comercio e inversiones", "energía y transportes" y "combate a amenazas comunes”; en segundo lugar, respondiendo a la promoción de los valores de

\footnotetext{
61 Idem.

${ }^{62}$ Ibidem, p. 71.

63 Ibidem, p. 72.
} 
la buena gobernanza, aparecen áreas como "derechos humanos, Estado de derecho, buena gobernanza y democratización”, “juventud y educación” y “diálogo intercultural”. De acuerdo con la Estrategia de 2007, los principales objetivos de la cooperación europea con Asia central han sido: garantizar la seguridad y la estabilidad de los países de la región, ayudar a erradicar la pobreza e incrementar los niveles de vida en el contexto de las metas del Desarrollo del Milenio, facilitar y promover una cooperación más cercana tanto al interior de Asia central como entre la UE con Asia central, particularmente en las áreas de energía, transporte, educación superior y sectores ambientales. ${ }^{64}$ De la misma manera, la nueva Estrategia trató de enlazar sus objetivos con otras iniciativas de cooperación regional formuladas desde la UE, especialmente en lo que se refiere al tema la seguridad energética en tanto una prioridad creciente de la agenda europea: para Schmitz puede considerarse que el documento de 2007 tuvo la intención de orientar las relaciones con la región para conformar una asociación estratégica "similar a la Asociación Euro-mediterránea y a la Dimensión del Norte y formar un enlace conceptual con la Estrategia para Asia central; ambos documentos se refieren uno al otro de manera explícita". ${ }^{65}$

El escenario internacional posterior a 2001 ha determinado que las políticas de la UE hacia Asia central mantengan como prioridad a las cuestiones de seguridad, algo que se fortaleció tras la instrumentación de la Estrategia Europea de Seguridad de 2003; como consecuencia, la aproximación de la UE hacia los países centroasiáticos se ha mantenido en una especie de pragmatismo forzado, a pesar de las justificadas protestas europeas por los numerosos casos de violaciones de derechos humanos y la falta de democracia en los regímenes autoritarios de la región:

Instrumentos de fuerza (como la condicionalidad negativa o las sanciones) son usados difícilmente; incluso el principio de condicionalidad positiva de la UE, el cuál ha sido establecido en casi todos los comunicados, documentos estratégicos y acuerdos con los países de Asia central, carece de una observancia... ${ }^{66}$

64 Comisión Europea/Consejo Europeo, op. cit., pp. 26-29.

65 Schmitz, Andrea, op. cit., p. 72.

${ }_{66}$ Warkotsch, Alexander, "The European Union and Democracy Promotion in Bad Neighbourhoods: the Case of Central Asia”, European Foreign Affairs Review, vol. 11, núm. 4, 2006, p. 324. 
Una prueba política para el pragmatismo europeo en su aproximación a Asia central ocurrió recientemente, con la ocasión de la revuelta que derrocó al presidente de Kirguistán Kurmanbek Bakiev en abril de 2010, un proceso en que la UE adoptó una postura discreta y se limitó a emitir comunicados sobre la situación de los derechos humanos durante los enfrentamientos que derrocaron a Bakiev y en los que resultaron muertos decenas de opositores. La naturaleza de la aproximación europea hacia la región centroasiática origina un nuevo debate entre la obligación política de la UE en mantener una coherencia con sus principios políticos y la existencia de contextos que justifican políticas pragmáticas que flexibilicen los intereses normativos de Europa.

Como expresión de una aproximación que aspira a ser pragmática, en la Estrategia de 2007 se otorga una dimensión instrumental al concepto de buena gobernanza presentándola de una "manera tecnocrática", con el fin de enfocarla en asuntos concernientes a las reformas administrativas y en la transparencia de las finanzas publicas además del Estado de derecho, los procesos democráticos, la sociedad civil y el respeto a los derechos humanos. Sin embargo, para Schmitz el uso tecnocrático del concepto de buena gobernanza ha demostrado limitantes a la hora de estimular las prácticas democráticas en regímenes autoritarios como los centroasiáticos.

Lo anterior queda evidenciado en la apertura que han demostrado los países centroasiáticos al establecer cierto diálogo político con la UE, motivada no por un interés en la aceptación de los valores europeos (y la reforma de los sistemas políticos) sino con el fin de encontrar nuevos interlocutores más allá de Rusia o China, facilitando una mayor diversificación de las relaciones internacionales de los países de Asia central. ${ }^{67}$ Realizando una evaluación, para Schmitz el documento de 2007 posee dos defectos fundamentales: en primer lugar, se centró en el aspecto burocrático del funcionamiento de la relación entre la UE y los países centroasiáticos, es decir, tratando de solucionar las contradicciones y la falta de consistencia institucional acumuladas por los fallos de los programas de ayuda instrumentados desde los años noventa. En segundo lugar, la indiferencia de los países miembros en la planeación de la nueva estrategia debilitó, justamente, el carácter "estratégico" del documento:

${ }^{67}$ Hoffmann, Katharina, op. cit., p. 92. 
El resultado es esencialmente una declaración de intenciones en lugar de una estrategia en el sentido estricto del término. Por ello, son declaradas las metas comunes (como la estabilidad, la prosperidad y la libertad) y los intereses (seguridad y desarrollo económico regional así como la integración de la región en la economía mundial) al mismo tiempo que se enlistan los instrumentos para su realización. Sin embargo, los dos elementos constitutivos de una estrategia se encuentran ausentes: en primer lugar, un enfoque a largo plazo de las metas estratégicas que la UE busca en Asia central; en segundo lugar, un esquema realista y coherente para la realización de esas metas. ${ }^{68}$

La ausencia de una visión a largo plazo en el contenido de la agenda forma parte de la asimetría estructural de la aproximación europea hacia la región centroasiática, quizá por ello la UE siga percibiendo a Asia central como una región parte del mundo ex soviético, soslayando su condición poscolonial en tanto países que asumieron su soberanía hace veinte años: "El documento es principalmente una declaración de intenciones políticas de un alto valor simbólico y no menos, pero también, no más que eso". ${ }^{69}$

\author{
IV. LAS POTENCIAS EXTERNAS Y EL PROCESO DE APROPIACIÓN \\ COnCEPTUal de Asia CEnTRal durante la Posguerra Fría: \\ UNA COMPARACIÓN CON EL CASO EUROPEO
}

Es posible afirmar que desde 2001 los países de Asia central han despertado una atención continua por parte de Europa; en el trabajo se ha descrito cómo la políticas de aproximación que ha articulado la UE hacia dichos países han estado determinadas por un conjunto sucesivo de imágenes ideales o hipótesis elaboradas alrededor de la región centroasiática, de acuerdo a las necesidades y prioridades europeas, las cuales han sido formuladas en diferentes coyunturas: particularmente estas ideas han generado un campo más o menos amplio de interpretaciones, categorías e incluso imágenes autorreferenciales para encontrar una definición de la región centroasiática en términos europeos.

\footnotetext{
68 Schmitz, Andrea, op. cit., p. 75.

69 Ibidem, p. 71.
} 
Una consecuencia trascendental en la trayectoria del conjunto de políticas europeas sobre Asia central, bajo los criterios anteriores, se ha visto manifestada en una falta de consistencia de las instituciones europeas en su aproximación hacia dicha región; en cierta manera, el discurso europeo sobre Asia central ha privilegiado sus funciones simbólicas (la idea europea sobre la región) en lugar de centrarse en una materialidad institucional para alcanzar los planes concretos de la UE: como afirma Ertan Efegil sobre la eficacia institucional de la aproximación europea: “... las respuestas políticas permanecieron esencialmente como un método de coordinación intergubernamental 'dependiente de las palabras' en lugar de ocuparse inclusive por el desarrollo de los instrumentos comunes más blandos". ${ }^{70}$ La importancia de esta carga simbólica o discursiva se ha hecho presente tanto para coordinar una agenda de cooperación para el desarrollo o en las temas de seguridad.

Con fines metodológicos se pueden describir dos periodos diferenciados en la aproximación europea a Asia central de acuerdo a la formulación de conceptos sobre la región.

\section{Periodo 1991-2001}

Como se ha mencionado, las primeras imágenes ideales de la UE iniciaron con la definición que interpretaba a Asia central como una región de países sin mucha diferencia entre ellos y necesitados de la ayuda económica y técnica de la UE, con el fin de que iniciaran sus procesos de reformas y transición a una economía de mercado, de forma similar a otros miembros de la CEI; posteriormente esta interpretación fue matizada, ya que si bien los países centroasiáticos conformaban un conjunto de países ex comunistas, estos debían agruparse de forma separada a los países de Europa del Este, ya que no podían ser considerados para ser admitidos como candidatos en el proceso de ampliación de la UE: es decir, la naturaleza de la región centroasiática comenzó a ser elaborada, en términos europeos, mediante un elemento autorreferencial,

70 Efegil, Ertan, “The European Union's New Central Asia Strategy”, en Kavalski. Emilian (ed.), The New Central Asia.The Regional Impact of International Actors, Singapur, World Scientific Publishing, 2010, p. 75. 
en este caso perteneciente a un proceso de construcción institucional del proyecto de integración como el proceso de ampliación (que por extensión contribuía a establecer los límites geográficos e identitarios de la Europa unida). Durante este primer periodo igualmente fue clara la ausencia de una distinción que considerara a los países centroasiáticos en tanto unidades políticas con características propias, con particularidades culturales y necesidades económicas específicas, al extremo que las regiones del Cáucaso y Asia central podían ser visualizadas como una región amplia con las mismas problemáticas básicas.

Una de las principales dificultades institucionales de la UE para coordinar políticas efectivas hacia los países de la región, persistente hasta el momento, ha consistido en que los mecanismos institucionales de la UE mantuvieron "una tendencia a pensar que Asia central no es constituida por Estados soberanos sino que es una región unificada". ${ }^{71}$

Durante la segunda mitad de los años noventa, conforme avanzaban los procesos de democratización en Europa del Este, los criterios anteriores fueron nuevamente matizados: entonces en la región de Asia central fueron identificados un conjunto de países con gobiernos autoritarios, o con transiciones democráticas inconclusas (una diferencia sustancial respecto a los países ex comunistas europeos), pero aun susceptibles de recibir ayuda económica y asistencia técnica mediante los criterios políticos de la condicionalidad, también aplicados a otros receptores de la asistencia europea para el tercer mundo. Sin embargo a pesar de que la ayuda condicionada incluyó con mayor énfasis temas pertenecientes a la agenda de la buena gobernanza, las prioridades europeas en Asia central siguieron siendo la apertura económica y la instauración de economías de mercado en la región.

\section{Segundo periodo (2001-)}

Durante los primeros años del siglo XXI, la interpretación europea sobre Asia central se modificó, ahora bajo los criterios desencadenados

71 Norling, Nicklas, "EU's Central Asia Policy: The Adoption of a New Strategy Paper 2007-2013", Central Asia and the Caucasus. Journal of Social and Political Sciences, Luleå, núm. 3 (45), 2007, p. 14. 
por las coyunturas bélica y de seguridad originadas tras los atentados terroristas contra Estados Unidos en 2001: entonces los países centroasiáticos fueron considerados socios necesarios de los aliados occidentales en su lucha contra el terrorismo o como una suerte de "última frontera" frente al extremismo religioso, especialmente el islámico. De esta manera, Asia central se convirtió en un territorio de frontera con quien era conveniente mantener buenas relaciones, lo que redujo la tensión política derivada de las exigencias de la ayuda condicionada.

La segunda etapa de la relación euro-centroasiática se ha encontrado determinada por tres prioridades claramente identificables: por la necesidad europea de diversificar sus mercados energéticos para evitar una dependencia permanente del mercado del gas ruso, por la velocidad con la que se han incrementado los vínculos comerciales de las economías europeas con las de Asia del Este y debido a la aproximación geográfica que adquirió el territorio que conforma a la UE con Asia central, como consecuencia de los procesos de ampliación de 2004 y 2007 (con el surgimiento de nuevos riesgos en materia de lucha contra el crimen organizado y contra el extremismo islámico). Con el proceso de ampliación y la instrumentación de la PEV se ha desarrollado un nuevo discurso que considera a Asia central como "la vecina de nuestros vecinos": la región centroasiática dejó de considerarse distante o marginal para ocupar un lugar cada vez más relevante en la política exterior europea y sus necesidades de inserción en el sistema internacional. Sin embargo, como menciona Shao Yuqun, la nueva percepción geopolítica hizo que los programas de ayuda desarrollados hasta entonces, contenidos en el Programa TACIS o los PCA, comenzaran a mostrar sus insuficiencias ante las nuevas prioridades de la acción exterior europea "puesto que eran demasiado selectivos para demostrar alguna efectividad en el plano regional". ${ }^{72}$

Los elementos anteriores han orientado a la UE a elaborar una política tendiente a priorizar la cooperación en materia de la seguridad y la energía con sus nuevos vecinos centroasiáticos en conjunción con las preferencias normativas de la buena gobernanza promovidas en la región; la consecuencia de estas nuevas prioridades ha sido un mayor desplazamiento de las preocupaciones sobre la falta de democracia o

72 Shao Yuqun, op. cit. , p. 4. 
la situación de los derechos humanos en esos países, así como una disminución en los criterios para otorgar la ayuda condicionada, si bien el discurso oficial europeo todavía reconoce a sus preferencias normativas como una de sus prioridades en Asia central; de acuerdo a la Estrategia Política para Asia Central de 2007: "La UE considera a la seguridad y la buena gobernanza como sus objetivos clave en Asia central. Una de los objetivos centrales de la Estrategia Europea de Seguridad consiste en la necesidad de promover un anillo de países bien gobernados ubicados hacia el este de la Unión Europea”. ${ }^{73}$

Sin embargo, la relación de la UE con los países de Asia central ha generado una paradoja, pues no obstante la cercanía geográfica entre ambas regiones, hasta el momento la UE no ha podido elaborar una estrategia política "coherente" hacia los países centroasiáticos, como menciona Nicklas Norling: “... considerando que mientras los intereses substanciales de Europa en Asia central se han vuelto más evidentes, la ausencia de una estrategia resulta más clara”. ${ }^{74}$ A las preocupaciones en materia de seguridad, en el contexto de la intervención de la OTAN en Afganistán, debió agregarse la creciente necesidad europea por diversificar sus mercados de proveedores de energéticos dada la inflación registrada en los precios internacionales del petróleo durante el periodo 2003-2008 o la "guerra del gas" que ha alterado el abastecimiento del combustible a Europa bajo la responsabilidad de Rusia entre 2005 y 2008.

Por otra parte, debe tomarse en cuenta que la sucesión de imágenes ideales sobre Asia central elaboradas desde Europa no representa un caso único: Asia central también ha sido interpretada mediante conceptos convenientes a los intereses de otras potencias externas con intereses en la región, particularmente por parte de Rusia, Estados Unidos o la República Popular China (RPCh). De esta manera, Asia central ha podido ser conceptualizada, interpretada y apropiada de manera múltiple de acuerdo a consideraciones basadas en la razón instrumental de cada potencia, y la manera como la región es integrada en los particulares proyectos de desarrollo nacional, inserción en el sistema internacional o expansión política, económica y militar de cada potencia.

73 Comisión Europea/Consejo Europeo, op. cit. p. 5.

74 Norling, Nicklas, op. cit., p. 7. 
La característica distintiva en el acercamiento inicial de la UE a la región centroasiática, en comparación con otras experiencias, reside en que dicha aproximación fue articulada inicialmente alrededor de las percepciones y expectativas derivadas de los procesos de cambio de régimen y transición política que tomaban lugar en el mundo ex comunista europeo y no sobre un conjunto de información basada en las características objetivas de la región y cada país centroasiático. Las primeras percepciones europeas sobre Asia central fueron un tanto difusas a lo que se agregó un hecho concreto: la "decisión de Rusia” de no seguir subvencionando los recursos públicos de todos los países centroasiáticos, incluyendo la energía, lo que provocó un desastre económico y social para la región. Como menciona Antonio Marquina:

En la Comisión Europea se conocía poco esta zona, aunque se esperaba de forma ilusoria que el periodo de desarrollo institucional de las nuevas repúblicas fuese corto, para lo que darían un apoyo vía el programa TACIS, y una vez que esto ocurriera, se podría proceder a la puesta en práctica de los acuerdos de cooperación y colaboración que el Consejo de Ministros consideraba que era necesario negociar con las nuevas repúblicas. ${ }^{75}$

Tras el declive económico producto de la desaparición de los servicios públicos soviéticos: "La miseria resultante impidió las necesarias reformas económicas y políticas que en un primer momento se habían considerado como relativamente sencillas y rápidas". ${ }^{76}$ De esta manera, la UE se presentó como un donador de ayuda en teoría necesario para la región debido a la desaparición de la URSS: sin embargo, hasta el momento los países de la región no han buscado a un sustituto de la URSS en cuanto a donador de ayuda, debido tanto para preservar su soberanía como por las dificultades que enfrentaron tras la desaparición de la asistencia soviética; la renuencia a privilegiar a un solo donador en específico es más clara observando la presencia de otras potencias en la región como Estados Unidos, Rusia o China y la política a favor del multilateralismo mantenida por la mayoría de los países de la región.

75 Marquina, Antonio, "El Cáucaso y Asia central en la política de la Unión Europea”, Cuadernos constitucionales de la Cátedra Fadrique Furió Ceriol, Valencia, núm. 49, 2004, p. 215.

76 Ibidem, pp. 215 y 216. 
Las dinámicas de competencia geopolítica entre potencias en Asia central, durante los años noventa y la primera década del siglo XXI, han involucrado principalmente a tres países: China, Estados Unidos y la Federación Rusa además de otros poderes regionales como India, Irán y Turquía. Sin embargo, debido su a condición postcolonial y a su incipiente proceso de formación nacional, se puede afirmar que los países centroasiáticos han preferido mantener sus soberanías nacionales frente a los intereses de las potencias externas al mismo tiempo que se han mostrado escépticas respecto a los discursos de competencia geopolítica formulados desde las metrópolis.

Los discursos elaborados por las potencias son diversos y encarnan, en una doble dinámica, tanto el conjunto de argumentos reales o retóricos que buscan justificar su presencia en Asia central así como la construcción imaginaria usada para elaborar una particular idea sobre la región: es decir, las hipótesis sobre la región centroasiática a través de las cuales puede ser instrumentalizada de forma más útil y coherente para los planes estratégicos (en seguridad y defensa), los intereses económicos y las particulares políticas de desarrollo de las potencias externas.

Hasta el momento los discursos de aproximación que las tres potencias han formulado hacia la región centroasiática han desarrollado orientaciones que pueden ir desde los extremos discursivos de la integración de alianzas de seguridad en un proceso de competición geopolítica permanente y balances de poder, como la hipótesis realista del Nuevo Gran Juego centroasiático generado en Estados Unidos, hasta los planes de expansión económica de China en Asia central, conceptualizados en la diplomacia económica (poder blando) alrededor del discurso de la Nueva Ruta de la Seda, ofrecido por la RPCh a los países de la región desde 1994.

El politólogo uzbeco Farkhod Tolipov propone tres "hipótesis" o tipos ideales para describir los discursos imaginarios elaborados sobre la región centroasiática por parte de las potencias de acuerdo a sus intereses estratégicos y a sus fines instrumentales:

1) La primera hipótesis considera a Asia central como una zona colchón o amortiguadora (buffer zone), la cuál se relaciona con los 
intereses nacionales de la Federación Rusa en una dinámica ofensiva/defensiva: de manera ofensiva, el poder ruso se ha asumido como el protector histórico de la región centroasiática, con el consiguiente derecho de acceso a sus recursos económicos y a la influencia en sus procesos políticos; de manera defensiva, Asia central resulta ser un escudo que protege a Rusia de la presión externa causada por sus rivales geopolíticos "primeramente el Imperio Británico y posteriormente Estados Unidos". ${ }^{77}$ En la actualidad las imágenes rusas sobre Asia central se refuerzan debido a la intervención militar de la OTAN en Afganistán y al temor a que este país se convierta en una base militar permanente de los aliados occidentales. ${ }^{78}$

2) La segunda hipótesis se refiere a la imagen que transforma a Asia central en un cordón sanitario (sanitary cordon), la cual se identifica con los intereses de Estados Unidos; dicha hipótesis:

... persigue una estrategia de pluralismo geopolítico y tiene la intención declarada de prevenir que cualquier otro poder invada a Asia central. Mientras dicho estatus admite la presencia tenue de otras potencias, enfatiza su posición categórica en influir sobre las decisiones a la hora de permitir la entrada de otros actores.

77 Tolipov, Farkhod, “'Geopolitical Stipulation of Central Asian Integration”, Strategic Analysis, Nueva Delhi, vol. 34, núm. 1, 2010, p. 106.

78 El ex director del Instituto de Estudios Estratégicos de Rusia Evgeni M. Kokozhin, desde su punto de vista, explica las preocupaciones de Rusia sobre este tema: "En el mundo anglosajón ha habido una larga tradición que considera a Afganistán, Xinjiang y Tíbet como parte de Asia central. Algunos académicos estadounidenses incluso consideran que Afganistán resulta ser el corazón de la región, mientras otros académicos occidentales también incluyen a parte del norte de la India y Pakistán. Desde el punto de vista geopolítico, Afganistán es un territorio muy importante, quizá mas importante que Irak. Quizá por esta razón, mientras que Estados Unidos se repliega de Irak al mismo tiempo refuerza sus posiciones en Afganistán. La guerra en Afganistán no es solo la guerra contra el terrorismo; también es la preparación geopolítica para un nuevo orden internacional después de la creación de un escudo de defensa de antimisiles en la zona. Entonces, Afganistán puede convertirse en la base para ejercer toda clase de presión e influencia sobre otros actores regionales: China, India, Irán y Pakistán”. Kokozhin, Evgeni M., "Geopolitical Importance of Central Asia: Russian View”, Strategic Analysis, Nueva Delhi, vol. 33, núm. 4, 2009, p. 480. 
No obstante su énfasis en la necesidad de una competencia geopolítica entre potencias, el modelo Nuevo Gran Juego resulta ser incluso más cooperativo que la imagen de "zona colchón". ${ }^{79}$

3) La tercera hipótesis es la que considera a Asia central como una plataforma para los proyectos de expansión de la potencia, la cual se relaciona con mayor claridad con los intereses de la RPCh; según Tolipov, de acuerdo a esta imagen la región centroasiática es considerada como la "retaguardia de China" y este país parece dispuesto a usarla como su plataforma de expansión, principalmente económica, hacia el occidente, relacionándola con sus proyectos de desarrollo en la provincias fronterizas de Xinjiang y Tíbet (el desarrollo de estas regiones es necesario para continuar con el proyecto de modernización chino así como fundamental para evitar los movimientos de secesión territorial que pueden amenazar el futuro de la RPCh). El movimiento de expansión chino puede tomar dos formas: "Expansión territorial o expansión de sus zonas de influencia económica. Sin embargo la primera es la que parece menos probable". ${ }^{80}$

Sin embargo, de acuerdo a Tolipov, los tres escenarios anteriores han aparecido como "totalmente inaceptables" para las aspiraciones de soberanía nacional de los países centroasiáticos. ${ }^{81}$ Puede considerarse que dicha resistencia ante la intervención de los poderes externos en los asuntos de política interna igualmente ha determinado la aproximación europea hacia la región centroasiática a lo largo del tiempo: a partir de dicho contexto, la UE ha tenido que elaborar su propio discurso de aproximación hacia la región centroasiática, algo determinado también por la preferencias normativas de la UE.

Resulta claro el contraste entre el carácter explícito y la madurez de las hipótesis de las tres potencias descritas por Tolipov en comparación con el tratamiento que la región centroasiática ha recibido en términos europeos: lo anterior se debe a que la aproximación europea se encuen-

\footnotetext{
79 Tolipov, Farkhod, op. cit. p. 106.

80 Idem.

${ }^{81} \quad$ Ibidem, pp. 106 y 107.
} 
tra determinada por sus procesos de integración política y construcción institucional así como los valores y las normas de la buena gobernanza que los orientan.

La identificación de los discursos elaborados desde Europa sobre Asia central, en medio de los planes y objetivos de otras potencias, ejemplifican un debate recurrente sobre la naturaleza de la política exterior europea, consistente en comparar la importancia económica y comercial que posee la UE frente a sus capacidades políticas y militares reales y la incidencia que tienen estas características en la formulación de su política exterior (un problema resumido en el popular lugar común: "en el mundo Europa es un gigante económico y un enano político”).

Para Juha Jokela, una manera de dilucidar la función que desempeña la UE en el sistema internacional actual, con especial referencia a los países asiáticos, consiste en distinguir entre dos modalidades por medio de las cuales puede ejercer su poder: a) como una potencia-modelo (model-power); b) como una superpotencia:

De acuerdo a Jokela la idea de concebir a la UE como una potenciamodelo probablemente sea una opción que prefieran los funcionarios europeos, lo cual puede servir para legitimar la orientación de la acción exterior europea en tanto que sea coherente con sus propios valores y normas: como es conocido, la política exterior de la UE hace extensiva las normas que han guiado a su proceso de integración para difundirlas en el sistema internacional (como en el caso de los derechos humanos, Estado de derecho, libertad, libre mercado, democracia, etcétera):

Es sugerido que estos desarrollos poseen lecciones que son importantes no sólo para Europa sino para todo el mundo. El mundo debería inspirarse en la experiencia europea y la UE debería mostrarse activa en la difusión de este modelo. Estas ideas son reflejadas claramente en las declaraciones de la UE y son apoyadas por los Estados miembros. ${ }^{82}$

Al asumirse como un poder normativo, la UE puede desarrollar una dinámica doble en la difusión de dichas normas: desempeña un papel

82 Jokela, Juha, "The European Union as an International Actor: Europeanization and Institutional Changes in the Light of the EU's Asia Policy”, en Gaens, Bart et al. (ed.), The Role of the European Union in Asia. China and India as Strategic Partners, Burlington, Ashgate Publishing, 2009 , p. 39. 
activo si encuentra interlocutores lo suficientemente receptivos para asumir e identificarse con sus normas o en caso de enfrentar a un interlocutor renuente a su aceptación, puede adoptar una posición pasiva, restringiendo la difusión de las normas a un carácter puramente discursivo o simbólico. Un ejemplo de las posiciones anteriores puede verificarse en la aspiración europea para convertirse en un modelo referencial para otros procesos de integración regional, especialmente para los casos de los procesos de integración de libre mercado ubicados en América Latina (relación asimétrica) o en el Sureste de Asia (relación simétrica) con quienes la UE mantiene relaciones de colaboración y diálogo.

Como contraste, en el caso de países con regímenes autoritarios ubicados en el tercer mundo, como los ubicados en Asia central, la intención europea para promover un proceso de integración regional inspirado en su propia experiencia ha sido nulo: es decir, hasta el momento no ha habido la intención por desarrollar encuentros multilaterales, constituidos incluso de manera simbólica, en la relación euro-centroasiática (como en el caso de las cumbres birregionales euro-latinoamericanas); de la misma forma, la UE no ha encontrado los rasgos de una relación suficientemente interdependiente que le permita influir en los países de Asia central mediante los criterios de la ayuda condicionada.

Para Jokela, el contraste entre los intereses estratégicos delineados por otras potencias frente al comportamiento normativo de la UE consiste en que "el comportamiento estratégico implica una consideración más explicita sobre cómo las metas políticas son traducidas en una acción efectiva" en comparación al proceso de toma de decisiones de los funcionarios europeos, el cual puede considerarse como "rutinizado":

Ha sido sugerido que la acción de la UE refleja un comportamiento "rutinizado" en lugar de uno estratégico. Como un actor rutinizado la UE se comporta de una manera preferiblemente premeditada reflejándose en la firme creencia de que la historia europea es una lección para todos... Aunque el comportamiento europeo obviamente se fundamenta en un profundo pensamiento y comportamiento estratégico, existen una cantidad de ejemplos de comportamiento rutinizado, [como ejemplo] se ha sugerido que el actual proceso de ampliación fue orientado por las necesidades de regulación relacionadas con el mercado único en lugar de las pre- 
condiciones políticas relacionadas con las gobernanza democrática y los derechos fundamentales. ${ }^{83}$

En la actualidad la UE ha asumido una política crecientemente pragmática hacia la región centroasiática debido al contexto internacional en flujo, las necesidad de tener una capacidad de actuación verificable en su periferia y sus propias necesidades estratégicas (en energía y seguridad) a lo cual debe agregarse, de una forma también relevante, la creciente presencia de potencias externas en Asia central que podrían desplazarla de la región o al menos subordinar a la UE a un proceso de competición geopolítica ajeno a las normas europeas.

Las condiciones anteriores han implantado la necesidad de instrumentar políticas guiadas por criterios pragmáticos en la relación con Asia central aprovechando un proceso de cambio en el pensamiento estratégico europeo: "En términos de la creciente política exterior de la UE, el tipo de acción estratégica y sus objetivos son relevantes para la distinción entre la potencia-modelo y la superpotencia”. ${ }^{84}$ Sin embargo, la acción de asumir políticas pragmáticas como una forma de evitar un desplazamiento de Asia central posee algunos riesgos institucionales para el proyecto europeo, en tanto que el pragmatismo se encuentra orientado a resolver problemas en el corto plazo, mientras que el proceso de cambio en la relación euro-centroasiática forma parte de un proceso de transformación de naturaleza sistémica que atraviesa al sistema internacional en su conjunto: algo relevante en lo que se refiere al mantenimiento o la transformación de la estructura asimétrica de la relación. Este proceso de cambio igualmente se encuentra determinado por una crisis económica de larga duración como la iniciada en 2007 y por una inestable redistribución del poder mundial entre potencias consolidadas y emergentes.

La manera en que la UE pueda dilucidar y resolver este dilema, consistente en la aplicación de políticas pensadas a corto plazo o bien encauzando una reestructuración de la relación euro-centroasiática, de manera coherente con un proceso de cambio sistémico mundial, con seguridad será uno de los procesos definitorios en el desarrollo de las

83 Ibidem. p. 46.

${ }^{84}$ Ibidem. p. 40. 
relaciones internacionales en el espacio euroasiático a largo plazo (algo que también tendría influencia en las estrategias de otras potencias hacia la región).

Como un rasgo especialmente positivo de la aproximación europea hacia la región, debe reconocerse que no ha generado alguna dinámica de competencia geopolítica con relación a las otras potencias externas con intereses en Asia central. Por lo contrario, las posiciones europeas basadas en la buena gobernanza y la seguridad han representado una función de estabilidad en Eurasia central si son comparadas con otras políticas y sus discursos respectivos: la continuidad o no de esta función de estabilidad indirecta asumida por la UE puede representar un elemento relevante para la preservación de la paz en la región. En contraste, un riesgo potencial en un contexto de crisis como el que atraviesa el proyecto de integración europeo en la actualidad reside en que algunos países miembros de la UE decidan instrumentar sus propias políticas de aproximación para Asia central, respondiendo únicamente a sus intereses nacionales: algo que también podría tener consecuencias para el equilibrio establecido entre las potencias con presencia la región.

\section{CONSIDERACIÓN FINAL}

Actualmente la relación establecida entre la UE y los países de Asia central se mantiene en la ambigüedad de un conjunto de agendas bilaterales (entre la UE y cada país centroasiático) que resultan inefectivas para la capacidad de actuación política e institucional de la UE en la región. Lo anterior se debe a que el mantenimiento de la condición asimétrica de la relación entre la UE y los países centroasiáticos ha impedido la generación de una definición particular sobre la "asociación" que han establecido mediante los PCA.

Para la parte europea la prioridad ha consistido en desarrollar una relación asimétrica con los países centroasiáticos basada en la lógica de la relación con un receptor de ayuda ubicado en el tercer mundo, el cual recibe la asistencia bajo los criterios de la condicionalidad política, con el fin de llevar a cabo los procesos de transición y reforma exigidos por el donante. 
Debido a lo anterior, la parte europea ha preferido desarrollar un discurso propio que le ayude a construir una definición sobre Asia central modelada bajo sus propios términos, útil para sus intereses y fines, en lugar de establecer las condiciones que generen un diálogo entre los actores involucrados para que puedan construir un discurso de aproximación compartido. El discurso europeo de aproximación a Asia central ha otorgado una prioridad a la visualización de una región unitaria, construida artificialmente y más fácil de ser intrumentalizada en comparación con el conjunto de países diversos que la componen: esta realidad genera una contradicción, puesto que el desarrollo institucional de la UE ha reconocido que es indispensable la cooperación bilateral en el contexto de los PCA. El tratamiento recibido por los países centroasiáticos en tanto un objeto unitario, susceptible de ser apropiado, ha determinado el desarrollo de las relaciones ya sea mediante la ayuda condicionada o las políticas aplicadas de manera pragmática. 